\title{
52 TAMBÉM É UMA BOA IDÉIA: ALGUMAS ARTICULAÇÕES SOBRE A CARTA FREUDIANA DE MESMO NÚMERO
}

Mário Diógenes Poplade*

\begin{abstract}
RESUMO
Neste artigo, o autor, privilegiando uma leitura detalhada da carta freudiana de n. 52, propõe-se a estabelecer algumas articulações em relação ao seu conteúdo. Além da enorme importância para a Teoria Psicanalítica atual, caso alguém tomasse esta carta para prefaciá-la, necessariamente deveria considerar que a missiva dirigida por Freud ao seu amigo de então, Wilhelm Fliess, já continha os germens da inscrição sobre o recalque primário, sobre a pulsão, sobre a constituição do sujeito do inconsciente, assim como um esboço sobre o que viria a ser denominado mais tarde de estruturas clínicas.
\end{abstract}

Psicanalista do Centro de Psicologia Aplicada (CPA) da Universidade Federal do Paraná; Mestre em Educação pela Universidade Federal do Paraná; Membro da Biblioteca Freudiana de Curitiba; Coordenador de Grupos de Trabalho sobre a Teôria Psicanalítica da Biblioteca Freudianade Curitiba. E-mail:popla@datasoft.com.br 
A Carta 52 bem que poderia ser considerada aquela que se deve guardar sempre na manga, pois caso alguém a tomasse para prefaciá-la, neste prefácio necessariamente deveria constar que a missiva dirigida por Freud a Fliess já continha os germens da inscrição do recalque primário e da pulsão, da constituição do Sujeito do inconsciente, assim como de um esboço sobre o que viria a ser denominado mais tarde de estruturas clínicas.

LACAN, em entrevista realizada num programa veiculado pela televisão francesa ${ }^{1}$, entre muitas coisas, faz alusão à Teoria Freudiana de 1915 (A Teoria Topográfica). Nesta entrevista Lacan aborda e fala sobre recalque. Afirma que o afeto (um dos representantes psíquicos da pulsão), não possuindo qualquer possibilidade de ser recalcado, somente pode ser deslocado. E LACAN se pergunta: "Como poderia julgar-se deste deslocamento se não fosse pelo sujeito que supõe que não encaixa aí nada melhor que a representação?"

Pouco mais abaixo, nesta mesma página, acrescenta que: "a dita representação, especialmente reprimida, não é nada mais que a estrutura e precisamente enquanto ligada ao postulado do significante" (LACAN, 1977, p. 104-105)2. Aí remete o leitor à Carta 52 de Freud $^{3}$.

Se Lacan remete o leitor à Carta $n . .52$, não o faz por pouca coisa. Essa carta traz indicações importantíssimas e que merecem uma leitura detida e atenta. Nela, Freud nos fala sobre o mecanismo psíquico, que, segundo ele, "formou-se por um processo de estratificação" (FREUD, 1972, p. 317).

Fala também que o material presente em forma de traços de memória estaria sujeito a um rearranjo; estaria sujeito a uma

\footnotetext{
Posteriormente foi publicada pela Éditions du Seuil sob o nome Televisión (p. 104-105).

$\mathrm{Na}$ atualidade Televisión já foi traduzida e publicada pela Zahar editores.

${ }^{3}$ FREUD, S. Extratos dos documentos dirigidos a Fliess (1892-1899). In: SALOMAO, J. Edição standart brasileira das obras psicológicas completas de Sigmund Freud. Rio de Janeiro: Imago, 1972. v. 1 Publicações pré-psicanalíticas e esboços inéditos, p. 317.
} 
transcrição segundo novas circunstâncias. Contudo, deixa de acrescentar mais alguma coisa sobre quais seriam essas circunstâncias.

Adianta ainda que "o que há de novo a respeito da minha teoria - escreve ele, em 1896, a Flies - é a tese de que a memória não se faz presente de uma só vez, desdobra-a em vários tempos e é registrada em diferentes espécies de indicações" (FREUD, 1972, p. 317).

Freud declara não saber ao certo quantos desses "tempos" e/ou espécies de indicações há. Fala em pelo menos três e LACAN (1985, p. 178) faz algumas considerações sobre estes Niederchift (registros). FREUD então constrói como ilustração uma figura.

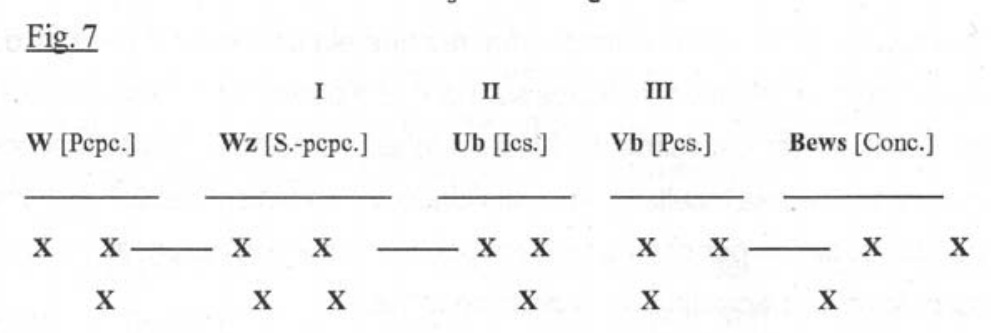

Nesta figura $7^{4}$, constam estes "registros" como:

W (Wahrnehmungen) - percepções.

W designa os neurônios nos quais as percepções se originam e Freud acrescenta ainda que "consciência (Bewusstsein) e memória se excluem mutuamente". Freud parece estar indicando aí que primeiramente, no humano, as percepções estariam mutuamente ligadas à memória. Esta, sendo detentora da capacidade de associar-se, facultaria ao material presente em alguns sistemas

Rio de Janeiro: Imago, 1972. v. 1 Publicações pré-psicanalíticas e esboços inéditos, $p$. 317. 
mnêmicos, a ordenação e a associação por simultaneidade e noutros, a associação e a ordenação por semelhança. Assim, uma mesma excitação, transmitida pelos elementos perceptivos, poderia fixar-se de uma maneira distinta e/ou inclusive associar-se a vários sistemas mnêmicos. Desta forma é que as inúmeras cadeias associativas guardariam a possibilidade de cruzarem-se numa mesma inscrição.

Essa capacidade de uma inscrição associar-se multiplamente é o que caracterizaria a riqueza das possibilidades de acoplamentos e cruzamentos, assim como também caracterizaria o vigor da estrutura psíquica no humano. Portanto, seria através desse meio que do lugar de uma inscrição, poder-se-iam cogitar vários sentidos por meio de várias cadeias às quais aquela inscrição estaria associada.

Conseqüentemente, na memória intuída por Freud, tudo o que lá se inscreve tem mobilidade e, assim, do lugar de uma inscrição pode-se inferir sua ligação com várias outras, uma vez que ela franqueia a possibilidade para a conformação de múltiplos sentidos. É a partir desta multiplicidade de sentidos, do estabelecimento destas duplas, triplas ou múltiplas inscrições que se supõe seja facultada a possibilidade da "conscientização": do homem pensar poder se pensar; do homem pensar poder "conscientizar-se de si", ou pelo menos acreditar na "sobredeterminação"...

Subsidiando-se de outros textos freudianos correlatos a este aspecto, LACAN (1976, p. 177) faz um pequeno resumo sobre Uma Nota sobre o "Bloco Mágico", um texto de $1924^{5}$. Este texto é uma metáfora freudiana para descrever como ele, Freud, intui o processo de inscrição na memória.

LACAN (1988, p. 67) também relata que Freud descreve a Wahrnehmung (esta impressão de mundo exterior enquanto

5 O texto está contido em FREUD, S. Uma nota sobre o Bloco Mágico (1924). In: SALOMÃO, J. Edição standart brasileira das obras psicológicas completas de Sigmund Freud. Rio de Janeiro: Imago, 1976. V. 19,0 Ego e o Id, p. 285 -293. 
bruta, original, primitiva) como uma Niederschrift (inscrição; registro) no sentido de algo que constitui signo e que é da ordem da escrita acrescenta: "é na medida em que a estrutura significante interpõe-se entre a percepção e a consciência (entre Wahrnehmung e Bewusstsein), que o inconsciente intervém, que o princípio do prazer intervém, não mais enquanto Gleichbesetzung (investimentos uniformes), função de manutenção de um certo investimento, mas na medida em que ele concerne às Bahnungen (trilhamentos). A estrutura da experiência acumulada reside aí e permanece aí inscrita". As Bahnungen (trilhamentos) inconscientes se constituem e podem ser consideradas então como as marcas primordiais, os primeiros traços diferenciais para o estabelecimento e edificação possíveis de uma realidade. Devido à constante tendência do aparelho psíquico à realização alucinatória da satisfação, torna-se obrigatório o estabelecimento de uma demarcação. Esta demarcação nada mais é que a Bahnung (trilhamento).

Retomando à leitura da Carta de Freud, verificamos que ele também discorre sobre estes "registros" como se produzindo em determinadas idades e cada vez mais organizados ${ }^{6}$ que, agora, segundo LACAN (1988, p. 67), "parecer-nos-á constituir um inconsciente". E continua: "pouco importa se Freud se engana ou não. Desde então vimos que podemos fazer o inconsciente e sua organização de pensamento remontarem a muito mais cedo".

Esta Wahrnehmung leva a se pensar em representações de coisas; na pulsão; na Beiahung (Afirmação); na Verneignung (Denegação), etc. Este $\underline{\mathbf{W}}$ vem'“falar" também de uma sutura existente, porque necessária, entre Simbólico e Real.

Ainda com referência à Carta 52 , Freud enumera como (I) as $\mathbf{W a h r n e h m u n g s z e i c h e n}=\mathbf{W z}=$ indicações de percepção, dispondo-se conforme as associações por simultaneidade, serão recalcadas e constituirão a base futura para a estrutura: a Ata do

${ }^{6}$ Conforme Figuras 8 e 9, p. 182.

Interação, Curitiba, v. 1, p. 139-151, jan./dez. 1997 
\$ujeito. Esta "Ata" compor-se-ia, pelo menos em tese, dos seguintes eventos que, na sua concomitância, deveriam ocorrer para que tal estruturação ou "Ata" fosse viabilizada:

- A demarcação nítida da separação entre a criança e a mãe, ou que ali uma separação se faz necessária, isto é, que seja delimitado que a mãe não é a criança e vice-versa;

- a possibilidade de presentificação de uma ausência (a questão da PRESENÇA/AUSÊNCIA);

- as primeiras impressões de representação de coisas;

- a entrada do $\mathbf{S 1}$ (passagem, através da mãe, do Nomesdo-Pai).

Antes, poder-se-ia dizer que a criança estaria sob a ameaça do desejo materno. Desejo voraz, ilimitado porque insaciável, alienante e "sedento" de completude. Esta relação inicial do idílio mãe/criança (época em que a relação guarda ares e assemelhase a uma célula narcísica onde os protagonistas tentam satisfazerse mutuamente) deverá ser rompida, desde que a separação acima aludida já tenha sido efetivada. A partir daí, possibilitar-se-ia a ocorrência daquilo que já descrevi em outro lugar ${ }^{7}$, ou seja: com a inserção do vivente na linguagem ocorrem no mínimo duas coisas: a primeira é que o Gozo Absoluto - a morte - o JA (o Gozo do Outro) tem seu caminho barrado, já que o objetivo até então era levar o aparelho ao apagamento de toda tensão pela descarga completa da energia pulsional. A segunda, é a possibilidade de um outro gozo, algo diferente da morte, algo da ordem da sublimação que, sendo uma das possíveis vicissitudes da pulsão, pode transformar-se em geração de vida, em criação. Aí já se está falando do gozo da falação, o - JF, o Gozo Fálico";

- o comparecimento da Bejahung e da Verneignung primordiais;

- a possibilidade de advento do vivente como apto ao desejo;

POPLADE, M. D. A estruturação do Sujeito. Revista Psicologia Argumento, Curitiba, v. 12, n. 215 , p. $50,1994$. 
- a Spaltung (hiância, fenda) propiciadora do aparecimento do \$ujeito. Aparecimento este que só pode ocorrer no terceiro tempo da pulsão, tempo do fazer-se ver; os outros dois tempos, o do se ver e o do ser visto, seriam o primeiro e segundo, respectivamente;

- a abertura para o início da entrada na ordem Imaginária (pensamentos);

- possibilidade de cristalização do Ego;

- entrada no Complexo de Éctipo, enquanto estruturaestruturante;

- possibilidade da ocorrência das primeiras identificações;

- possibilidade de Simbolização; configuração do Narcisismo primário;

- entrada no registro do Simbólico (enquanto discurso).

Segundo FREUD, este $\mathbf{W z}$ [Sist. pcpc. constitui-se no 1‥ registro (Niederschrift)] das percepções, sendo incapaz de assomar à Consciência.

Freud enumera como (II) - o Unbewusstsein - a inconsciência, onde estariam presentes e igualmente incapazes de assomar à consciência, traços e lembranças conceituais. $O$ Unbewusstsein configurar-se-ia como um segundo registro e seria disposto de acordo com outras relações, talvez, diz FREUD, causais.

- como (III) - 므- o Vorbewusstsein - pré-consciência (Ego), onde encontrar-se-iam as representações de palavras, representações verbais.

O Vorbewusstsein é também denominado por Freud como sendo uma consciência (secundária) do pensamento. Consciência esta que estaria ligada à experiência alucinatória das representações verbais, à emissão dos vocábulos.

Com relação a esta ascensão das representações de coisas para as representações verbais, LACAN (1988, p. 67) esclarece que "a elaboração que nos faz progredir de uma significação do mundo a uma fala que pode formular-se, a cadeia que vai do mais 
arcaico inconsciente à forma articulada da fala no sujeito, tudo isso ocorre entre Wahrnehmung e Bewusstsein (entre as indicações de percepção e consciência), como se diz entre dentes" (entre cuiret chair).

Entretanto, prossegue LACAN (1988, p. 67), "o que ocorre entre Wahrnehmung e Bewusstsein, deve, contudo, ter relação, pois é assim que Freud o representa para nós, como o inconsciente desta vez não apenas em função, mas em Aufban (extensão), em estrutura, como ele próprio se expressa fazendo a oposição".

Após, Freud apõe a Bewusstsein - consciência (onde encontrar-se-iam as representações de palavras mais as representações de coisas).

FREUD (1972, p. 319) relata ainda que: "Na fronteira entre essas épocas deve ocorrer uma tradução do material psíquico".

Um pouco mais abaixo, afirma: "cada transcrição subseqüente inibe a anterior e lhe retira o processo de excitação" (FREUD, 1972, p. 319). Isto seria uma possível pré-indicação do que viria a ser denominado por Lacan de os "primeiros" $\mathbf{S}(\mathbf{S}(\mathbf{S}(\mathbf{S}(\mathbf{S} 1$ - S2)?. Aí está algo que alguém poderia vir a desenvolver e aprofundar...

Depois, Freud vai adentrar na descrição dos grupos de psiconeuroses sexuais, vinculando suas respectivas aparições às idades que vão de 01 ano e meio até 14 anos, tecendo mais algumas outras considerações. 
Fig. 8

\begin{tabular}{l|c|c|c|c|c|c} 
& \multicolumn{1}{c}{4} & \multicolumn{2}{c}{8} & \multicolumn{2}{c}{$14-15$} \\
\hline $\begin{array}{l}\text { Psiquic. } \\
\text { Sexuais }\end{array}$ & Ia & Ib & II & III \\
II & & II & III \\
\hline
\end{tabular}

Fig. 9

\begin{tabular}{|c|c|c|c|c|}
\hline & $\begin{array}{l}\text { S.-pcpc. } \\
\text { Wz }\end{array}$ & $\begin{array}{c}\text { S-pcpc + Ics. } \\
W z+U b\end{array}$ & $\begin{array}{l}\text { S. } p c p c+1 c s+P c s \\
W z+U b+V b\end{array}$ & Idem \\
\hline & até 4 anos & até 8 anos & até $14-15$ anos & \\
\hline Histeria & $\begin{array}{l}\text { tendência } \\
\text { atua }\end{array}$ & compulsăo & $\begin{array}{l}\text { recalcado em } \\
\text { S-pcpc. [Wz] }\end{array}$ & \\
\hline $\begin{array}{l}\text { Neurose } \\
\text { obesidade }\end{array}$ & ............... & $\begin{array}{l}\text { tendência } \\
\text { atual }\end{array}$ & $\begin{array}{l}\text { recalcado nos } \\
\text { signos [Ub] ics. }\end{array}$ & \\
\hline Paranoia & ............... & ................ & $\begin{array}{c}\text { Tendência } \\
\text { atual }\end{array}$ & $\begin{array}{l}\text { recalcado nos } \\
\text { signos [Vb] pcs. }\end{array}$ \\
\hline Perversāo & $\begin{array}{c}\text { tendència } \\
\text { atual }\end{array}$ & $\begin{array}{c}\text { tendência } \\
\text { atual }\end{array}$ & $\begin{array}{l}\text { compulsāo } \\
\text { (tendencia) }\end{array}$ & $\begin{array}{l}\text { recalque impossivel } \\
\text { ou nāo intencionado }\end{array}$ \\
\hline
\end{tabular}

No concernente a estes desenvolvimentos, reservamo-nos a liberdade de supor que na atualidade haja ciência e consenso de que as descrições freudianas de então, baseadas numa mera cronologia, tiveram sua utilidade naquele momento histórico do desenvolvimento da teoria psicanalítica. Depois das publicações prépsicanalíticas, e em se tratando de dados inconscientes, a cronologia é totalmente dispensável neste sentido.

Ao desenvolver mais aprofundadamente seu raciocínio nessa carta, FREUD (1972, p. 321) faz alusão sobre a perversão, afirmando que esta é uma conseqüência onde a defesa (o efetivo 
Recalque da Castração) "não ocorreu antes de estar completo o aparelho psíquico, ou não ocorreu nunca".

Uma vez que seu interlocutor nesta época (1896) era Wilhelm Fliess (com quem Freud havia estabelecido uma transferência homossexual) tenta explicar por que determinadas vezes eclodia uma perversão e em outras a neurose. Aí então FREUD (1972, p. 322) acolhe como justificativa a "bissexualidade de todos os seres humanos".

Certamente Freud não se enganaria se porventura tivesse a oportunidade de contar com toda a riqueza do avanço, das articulações e dos progressos que presentemente permeiam a teoria psicanalítica. Pois, se ocorreu a Bejahung (Afirmação; entrada do S1), será bastante grande a possibilidade da utilização da Verneignung (Denegação) e de que ali tenha havido Verdrãngung (Recalque); o que configuraria o modo de defesa característico da Neurose, onde o Nome-do-Pai (este significante da Lei), estando em vigência, anola o nó borromeano. Nó este que, sendo composto pelos registros do Imaginário, Simbólico e Real, faculta inúmeras possibilidades de articulações. Algumas delas tivemos a oportunidade de indicar em um artigo intitulado Sobre o Sintoma: algumas considerações sob o enfoque psicanalítico ${ }^{8}$.

$\mathrm{Na}$ eventualidade de não-vigência da Bejahung (Afirmação), também não haveria a possibilidade de utilização da Verneignung (Denegação) e o modo de defesa diferentemente da Neurose, necessariamente seria a Verwerfung (Foraclusão), modo de defesa característico da estrutura clínica denominada Psicose.

Por outro lado, em se tratando da estrutura clínica denominada Perversão, ali supostamente teria ocorrido a Bejahung (Afirmação), mas de uma forma tal que propiciou que, ao invés de presentificar-se a Verdrãngung (Recalque), presentificou-se a Versagung (Recusa). Presentificou-se uma recusa da Castração.

8 POPLADE, M.D. Sobre o Sintoma: Algumas considerações sob o enfoque psicanalítico Revista Psicologia Argumento, Curitiba, v. 13, n. 16, p. 75-93, 1995. 
Através da recusa, o único viés possível para a configuração desta estrutura, será a Verleugnung (Desmentido; Renegação), que é o modo de defesa característico da Perversão, isto é, daquele que "escapou" da Castração. Contudo, sabe-se - através de Freud - que o humano contém já em si uma constituição sexual polimorficamente perversa. Asserção que se consubstancia no enunciado por LACAN (1985a, p. 194), ou seja: "o que se deve fazer, como homem ou como mulher, o ser humano tem sempre que aprender, peça por peça, do Outro".

Ainda sobre esta descrição em três grupos de psiconeuroses, LACAN (1985b, p. 180) relata que Freud "admite formalmente na Carta 52 que a Verneignung primordial comporta uma primeira sinalização (Wahrnuhmungzeichen). Ele admite a existência desse campo que chamo de significante primordial. Tudo o que ele diz a seguir nesta carta sobre a dinâmica das três grandes psiconeuroses às quais ele se prende, histeria, neurose obsessiva, paranóia, supõe a existência desse estado primordial que é o lugar eleito do que chamo Verwerfung".

Disso tudo poder-se-ia deduzir que toda e qualquer possibilidade de estruturação reside numa foraclusão primordial, ou seja, a possibilidade da não-existência da totalidade dos significantes no campo do Outro. Neste sentido, o S[A], o significante da falta de um significante no campo do Outro, a Castração Radical, seria a "falta de base", o Recalque Primário da humanidade. E o que fazer com isto? O que fazer com esta ausência? O que fazer com esta falta?

Enquanto leigo, enquanto vivente e mero mortal, tentar se pôr a trabalhar com o significante; tentar deixar-se trabalhar por ele e/ou aprender a fazer isto; identificar a sua diferença e marcarse como diferente e, assumindo uma posição sustentada em atos de palavra, labutar, produzir, criar.

Enquanto analista, ainda que mero vivente e mortal, e se houver analista, não se acovardar mediante sua própria destitui- 
ção subjetiva para, parafraseando o Mestre Alduísio M. de SOUZA (1996, p. 198) "se colocar como operador possível entre o outro [que não é o semelhante, mas portador do diferente] e o Outro" [enquanto diferença radical] e propiciar que o diferente e a diferença sejam valorizados e respeitados em suas posições e em seus atos de palavra e trabalhar com o significante; deixar-se trabalhar por ele; marcar-se como diferente em sua diferença e autorizando-se de uma posição sustentada em atos de palavra falada e escrita, inscrevê-la, labutar, produzir, criar, escrever...

\section{REFERÊNCIAS BIBLIOGRÁFICAS}

1 FREUD, S. Extratos dos documentos dirigidos a Fliess (18921899). In: SALOMÃO, J. Edição standard brasileira das obras psicológicas completas de Sigmund Freud. Rio de Janeiro: Imago, 1972. v. 1, p. 317 e ss.

2

A negativa (1925). In: SALOMÃO, J. Edição standard brasileira das obras psicológicas completas de Sigmund Freud. Rio de Janeiro : Imago, 1976. v. 19, p. 295-300.

3 Uma nota sobre o Bloco Mágico (1924). In: SALOMÃO, J. Edição standard brasileira das obras psicológicas completas de Sigmund Freud. Rio de Janeiro : Imago, 1976. v. 19, p. 285-293.

4 . Três ensaios sobre a teoria da sexualidade (1905). In: SALOMÃO, J. Edição standard brasileira das obras psicológicas completas de Sigmund Freud. Rio de Janeiro : Imago, 1969. v. 7, p. 135-252.

5 LACAN, J. Da Lei Moral. In: MILLER, J.-A. (Org.). O Seminário. Rio de Janeiro : J. Zahar, 1988. Livro 7, p. 91-107.

6 . Da rejeição de um significante primordial. In: MILLER, J.-A. (Org.). O Seminário. Rio de Janeiro : J. Zahar, 1985. Livro 3, p. 166-181. 
7 . Das Ding. In: MILLER, J.-A. (Org.). O Seminário. Rio de Janeiro : J. Zahar, 1988. Livro 7, p. 58-74.

8 _. O sujeito e o outro (I): a alienação. In: MILLER, J.-A. (Org.). O Seminário. Rio de Janeiro : J. Zahar, 1985. Livro 1, p. 193-204.

$9 \_$. Televisión. Barcelona : Anagrama, 1977. Xerocado.

10 LANGENCHEIDTS Universal-Wirtebuch Portugiesisch-Deustsch Portugiesisch, dicionário português - alemão - português. München, 1978.

11 LAPLANCHE, J.; PONTALIS, J. -B. Vocabulário da psicanálise. 9. ed. São Paulo : M. Fontes, 1986.

12 POPLADE, M.D. A Estruturação do \$ujeito. Psicologia Argumento, Curitiba, v. 12, n. 15, p. 37-55, 1994.

13 _. Sobre o sintoma: algumas considerações sob o enfoque psicanalítico. Psicologia Argumento, Curitiba, v. 13, n. 16, p. 75-94, 1995.

14 SOUZA, A. M. de. Do ódio ao amor e da covardia à valentia. In: Os impasses do amor. Porto Alegre : Artes Médicas, 1996. 